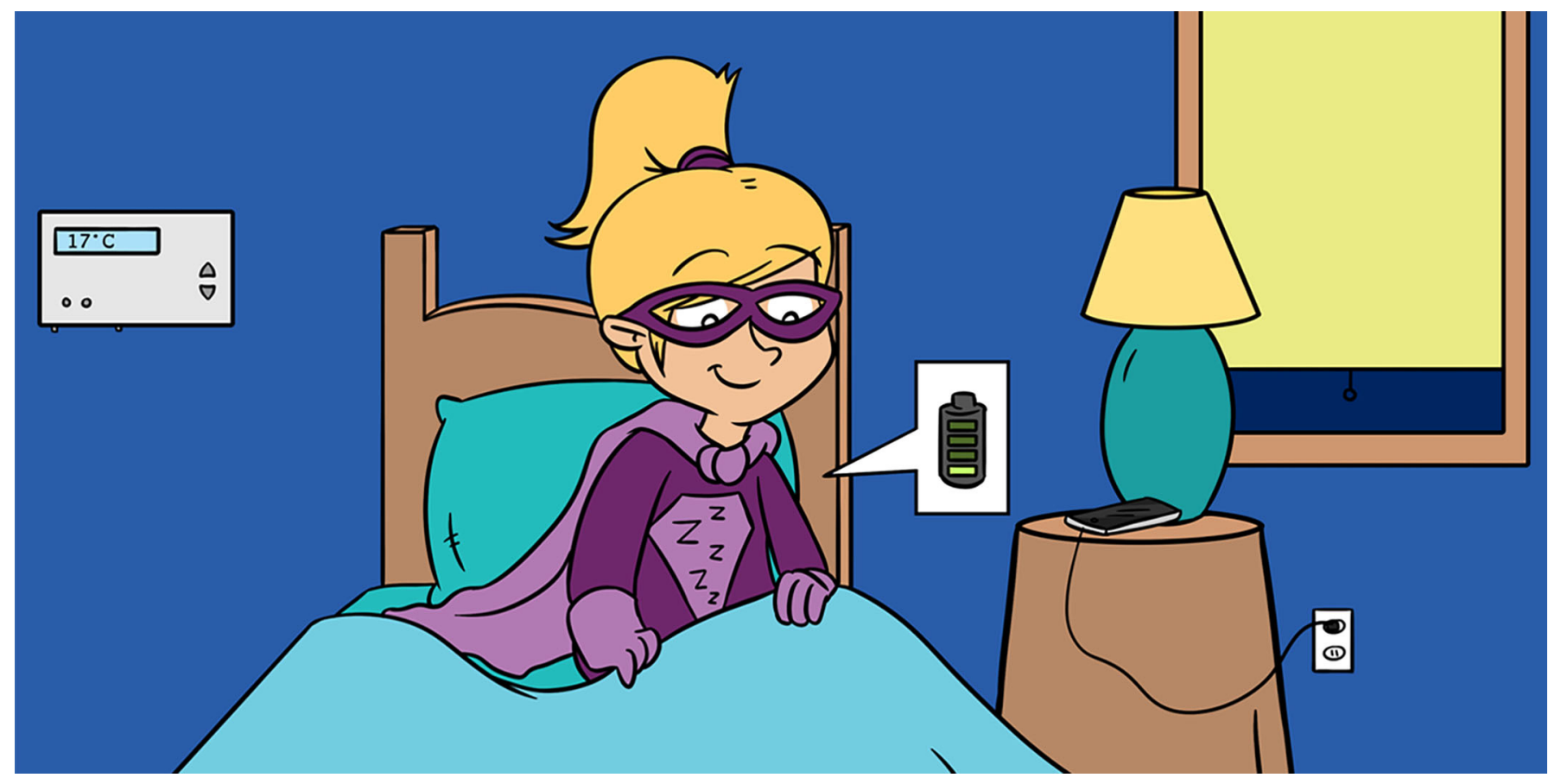

\title{
THE SUPERPOWERS OF OUR SLEEP
}

Laetitia S. Gaspar 1,2,3 , Bárbara Santos 2,3 , Ana Teresa Barros-Viegas 2,3,4, João Cardoso 2,3,5, Sara Varela Amaral ${ }^{2,3,4}$, Catarina Carvalhas-Almeida ${ }^{2,3}$, Ana Santos-Carvalho ${ }^{2,3,4}$, Cláudia Cavadas ${ }^{2,3,4,6}$ and Ana Rita Álvaro ${ }^{2,3,4^{*}}$

${ }^{1}$ Doctoral Programme in Experimental Biology and Biomedicine, Institute for Interdisciplinary Research, University of Coimbra, Coimbra, Portugal

${ }^{2}$ Center for Neuroscience and Cell Biology, University of Coimbra, Coimbra, Portugal

${ }^{3}$ Center for Innovation in Biomedicine and Biotechnology, University of Coimbra, Coimbra, Portugal

${ }^{4}$ Institute for Interdisciplinary Research, University of Coimbra, Coimbra, Portugal

${ }^{5}$ Doctoral Programme in Science History and Scientific Education, Institute for Interdisciplinary Research, University of Coimbra, Coimbra, Portugal

${ }^{6}$ Faculty of Pharmacy, University of Coimbra, Coimbra, Portugal

\section{YOUNG REVIEWERS:}

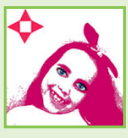

ALBA

AGE: 8

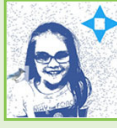

MARTINA

AGE: 8

Sleep is a fundamental function of the human body and it is crucial for our well-being and health. Most people are not aware of the importance of sleep. Only few adopt good sleep habits and sleep enough hours. This can lead to several consequences, such as problems with attention and memory and the development of develop. Respecting the number of hours of sleep needed by our bodies is crucial. The practice of good sleep habits can help us have a good night's sleep. However, some sleep problems can be more difficult to treat and a sleep specialist might be necessary to evaluate the situation and provide the appropriate treatment. Understanding 


\section{CIRCADIAN}

RHYTHMS

$24 \mathrm{~h}$ rhythms, regulated by biological clocks. For example, we go to sleep every $24 \mathrm{~h}$, so sleep/wake cycles have a circadian rhythm.

\section{SLEEP}

HOMEOSTASIS

Body mechanisms that control our need to sleep. It can be compared to a battery when it is fully charged we have more energy to carry out daily tasks; when it is empty, we have low energy and need to sleep to recharge the battery.

\section{BIOLOGICAL CLOCKS}

Internal clocks that regulate rhythmic cycles, like that of sleeping and waking.

\section{sleep and recognizing its importance will help you to sleep better and, ultimately, to have a healthy life.}

Sleep is essential for our well-being and health. It is a natural and basic function important for all organisms, from microorganisms to plants to humans, independent of gender, ethnicity, age, or culture. Even many years ago, Greeks and Romans worshiped gods associated with sleep, like Hypnos and his Roman equivalent, Somnus. Poor sleep is for humans what Kryptonite is to Superman: it weakens us. It is not by chance that, on average, one third of our day is spent asleep.

\section{HOW DO OUR BODIES KNOW WHEN TO SLEEP?}

Sleep is a fundamental biological function, highly regulated by (1) circadian rhythms, which are $24 \mathrm{~h}$ cycles that regulate the internal processes of our bodies, and (2) sleep homeostasis, which is the "battery" that regulates our energy levels and tells us when to sleep and when to awaken.

Circadian rhythms are cycles of approximately $24 \mathrm{~h}$ (from the Latin circa - "about" - and diem - "a day") that underlie all the biological and behavioral functions of our bodies. Each cell of the body acts as a biological clock, meaning that we all have multiple clocks inside our bodies, in all tissues and organs. These biological clocks organize the day into $24 \mathrm{~h}$, assigning specific functions, such as sleeping, to specific times of the day [1]. The timing of these clocks is set by a master clock located in the brain. Biological clocks are also affected by the condition of the body, such as its energy level, and on factors in the external environment, such as the amount of light or oxygen that is present or the amount of physical activity that is being performed. One example of a function regulated by biological clocks is body temperature, which is highest between 4 and 6 p.m. and lowest around 4 a.m. Activity and sleep patterns are also regulated by biological clocks. During the day, we are usually more alert and active: eating, playing, working, moving, etc., while during the night, we are less active and more predisposed to sleep.

When the day starts, we are often full of energy, but this energy decreases as the day goes on and at night we feel more tired, because our bodies need to sleep. During sleep time, the body uses energy to perform maintenance and repair, recharging our batteries (Figure 1). Superman also needs to recharge his powers under the sun. So, we sleep when our biological clocks tell us to, and when our batteries are empty. We wake up when our batteries are fully charged. This cycle repeats every $24 \mathrm{~h}$. 
Figure 1

Day/night cycle of the body. During daytime, with sunlight, we are more likely to perform activities that require more energy from our batteries (orange represents high energy levels in the battery).

Energy levels decrease throughout the day (yellow represents low energy in the battery), and at night, body temperature decreases and the brain produces a sleep signal called melatonin, telling us that we need to sleep to recharge our batteries.

\section{CHRONOTYPE}

Inner time preferences, set by our internal clocks, that determine when we are alert and productive during the day, either in the early morning hours or later in the day.

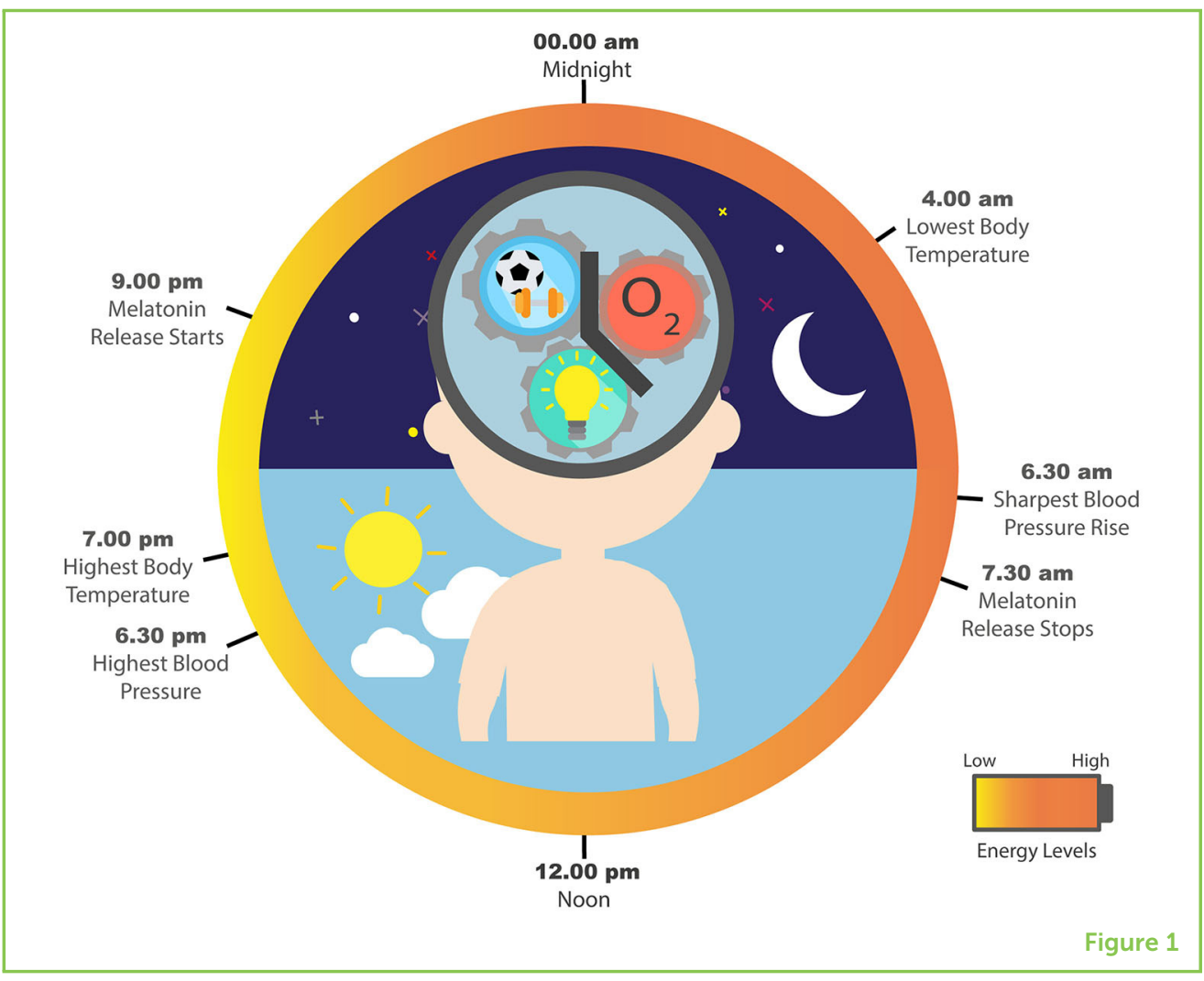

\section{SLEEP IS IMPORTANT!}

Most people are not aware of the importance of having good sleep habits, and only a few sleep enough hours to recharge their batteries. Sleeping less than what your body needs, which is called sleep deprivation, has severe consequences. In the short term, sleep deprivation can cause irritability, poor memory, concentration problems, headaches, and decreased immune defenses. In the long term, sleep deprivation can lead to an increased likelihood of developing certain diseases, including heart disease, obesity, and brain disorders. This also happens to Superman-his powers diminish when he is not exposed to the sun for a long time. The necessary number of hours of sleep needed to fully recharge our batteries varies from person to person and from age group to age group. The National Sleep Foundation, an American organization created to improve health and well-being through sleep education, recommends a suitable number of hours for each age group (Figure 2) [2].

Respecting the number of hours of sleep that our bodies need is very important. However, it is equally important to understand when we should sleep. Each of us has our own internal rhythm, called a chronotype, defined by our internal clocks. Our chronotype determines when we like to sleep [3]. Two main chronotypes, called morningness (being most active and alert in the mornings) and eveningness (being most active and alert in the evenings), are the two extremes. However, chronotype also changes as we 
Figure 2

Recommended sleep hours by age group, according to the National Sleep Foundation. The age ranges and recommended hours of sleep are shown along the purple line at the bottom of the figure.

\section{SLEEP HYGIENE}

Habits that lead to the right amount of sleep and good quality sleep.

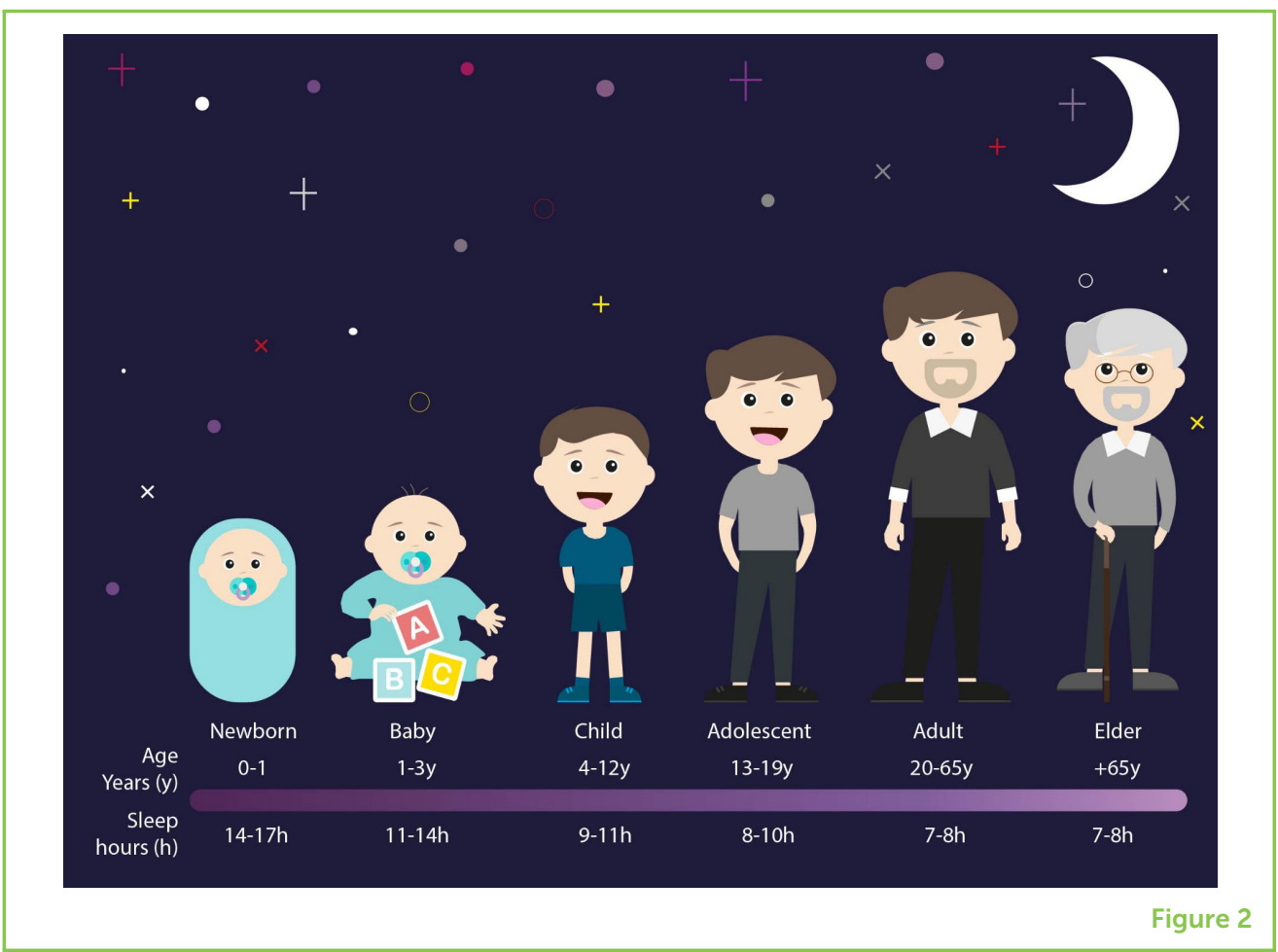

get older. Preteens and many elderly people usually experience morningness, while adolescents commonly experience eveningness. Indeed, many teenagers feel excessively sleepy during the day because they have difficulty falling asleep at night and waking up early in the morning.

\section{WHAT IS SLEEP HYGIENE?}

Taking too long to fall asleep, sleep disturbances, and daytime sleepiness are the most obvious signs of poor sleep hygiene. Good sleep hygiene includes habits and practices that help you to have a good night of sleep [4] (Figure 3). For example, going to bed and waking up at regular times. Even in exceptional cases, it is important to not go beyond $2 \mathrm{~h}$ from our regular routines, as it may deregulate our internal clocks and lead to difficulties falling asleep or waking up at specific hours. Physical exercise is also important to improve sleep quality. However, exercise acts as a stimulant and should be avoided close to bedtime. Similarly, other stimulants, such as chocolate and caffeinated drinks, keep our brains awake and should also be avoided close to bedtime.

Sleeping conditions should also be considered, such as the bedroom's temperature $\left(16-18^{\circ} \mathrm{C}\right.$ or $\left.61-64^{\circ} \mathrm{C}\right)$, its comfort, and its lighting. Bright light from lamps, cell phones, and TV screens should be turned off and electronic devices should be left out of the bedroom. Even before going to bed, the excessive use of electronics and bright lights should be avoided. Why? At dusk, our brains start to prepare our bodies 


\section{Figure 3}

Sleep hygiene. In order to have a good night's sleep, it is important to adopt sleep hygiene habits shown here.

\section{MELATONIN}

Called the sleep hormone; a chemical signal produced by the brain in response to the absence of light that makes us feel sleepy.

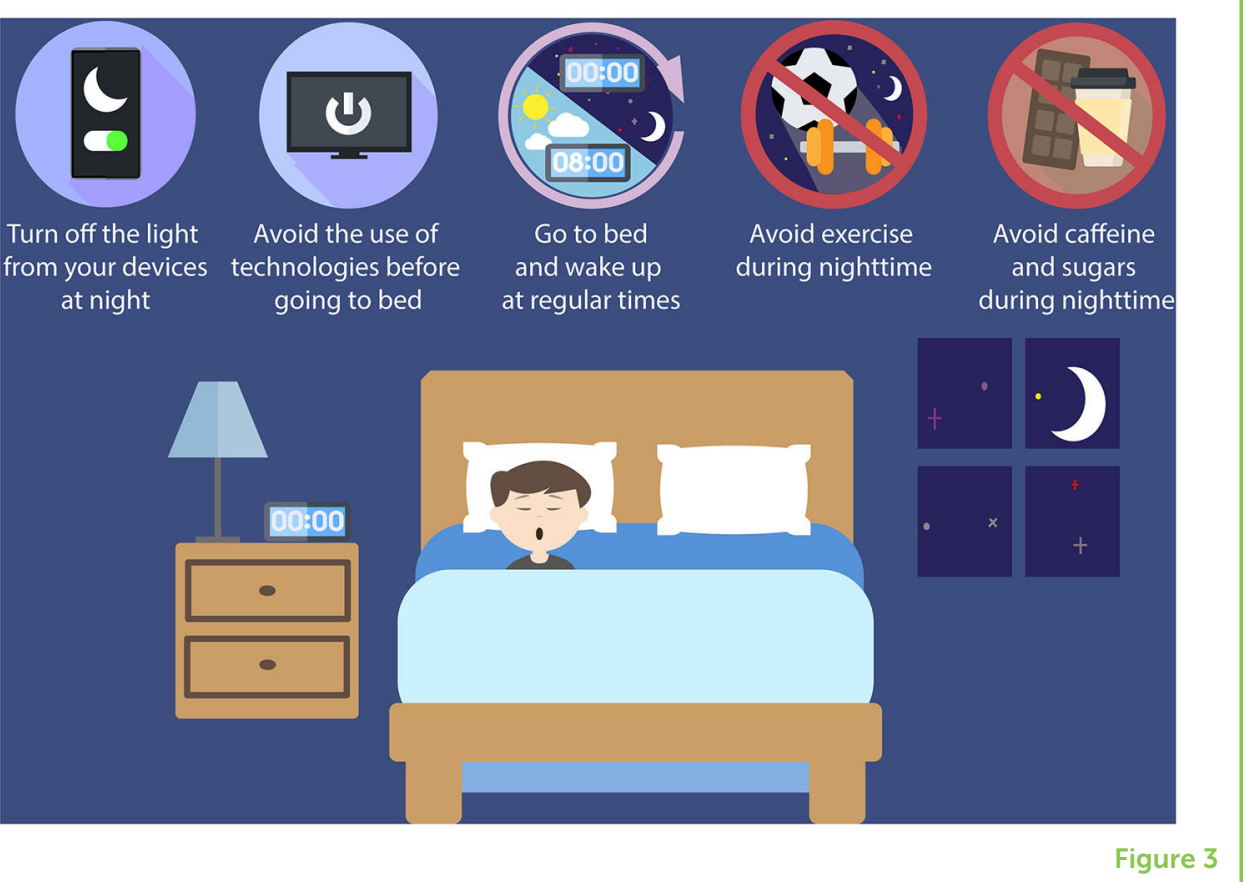

to sleep. The absence of intense light allows the production of a chemical signal that makes us feel sleepy. This chemical is called melatonin -the sleep hormone. Melatonin levels start to increase after sunset until the middle of the night (2-3a.m.). Then, melatonin levels begin to decrease until dawn. When we use electronic devices, the screens' light tricks the brain into thinking it is daytime again-the blue light emitted by screens is perceived by the brain as sunlight. This phenomenon delays melatonin production and consequently delays the start of sleep, similar to the Metropolis city danger signals that make Clark Kent awaken as Superman. Preparing ourselves for sleep by avoiding stimulating light helps us to train our bodies to sleep better and healthier.

\section{BE AWARE OF SLEEP DISORDERS}

Sleep disorders can cause difficulties with falling asleep or staying asleep, affecting the quantity and quality of our sleep. There are over 80 diagnosed sleep disorders [5] (Table 1). These can be caused by irregular sleep schedules, caffeine or alcohol, drugs, aging, a genetic predisposition, or the presence of other medical conditions, such as anxiety or brain disorders. We can imagine these disorders as Kryptonite, which weakens Superman and puts Metropolis city into serious danger.

If good sleep hygiene does not improve ongoing sleep difficulties, consulting a medical doctor or a sleep specialist should be the next step. First, the medical doctor will talk with the patient and evaluate his/her sleep habits, sleepiness during the day, presence of diseases, 


\section{Table 1}

Categories of sleep disorders and characteristics.

\section{Sleep Disorder Categories}

Insomnia

Sleep-related breathing disorders

Central disorders of hypersomnolence

Hypersomnia

Circadian Rhythm Sleep-Wake Disorders

Parasomnias

Sleep Related Movement Disorders

Other sleep disorders

\section{Characteristics}

Most prevalent sleep disorder worldwide. It consists on the inability to fall or stay asleep and/or a poor-quality sleep.

Involve difficulties in breathing during sleep, promoting frequent awakenings. It includes Obstructive Sleep Apnea.

Excessive sleepiness that is not caused by sleep problems or abnormal circadian rhythms.

Patients fall asleep at inconvenient or even dangerous places, such as at work or while driving.

The patient's sleep pattern (chronotype) is very early or very late, as Delayed Sleep Phase Syndrome.

Unwanted movements, behaviours or dreams while falling asleep, sleeping or waking up. These include sleepwalking (somnambulism), a sleep disorder that is very common in kids. Sleepwalking means getting up and walking or carrying out activities while sleeping. Most kids have sleepwalking episodes occasionally and outgrow it by the teen years or when they reach adolescence.

Conditions that cause simple involuntary movements, as leg movements, that disturb sleep or its onset.

Other disturbances that do not fit into any of the classification sections above but that impact on sleep, such as sleep disturbances associated with other medical conditions.

and current medication. If bad sleeping habits are detected, the doctor will advise the patient to change those habits to promote better sleep hygiene. If bad sleeping habits are not the problem, the patient must be further evaluated. Sleep might be monitored at home or at a Sleep Unit, using electronic devices. If a sleep disorder is diagnosed, there are several treatments that might be followed depending on the diagnosis. For example, a medical doctor might prescribe medication containing melatonin, if indicated. The status of the patient will be monitored by the Sleep Unit throughout the treatment and, depending on how the patient does, medication can be adjusted or removed. Other treatments might involve wearing devices during sleep, such as masks that help breathing while sleeping, or a psychologist to help people to sleep better.

To finalize, we recommend you to see this video where you can review all about sleep!

Video-Animation on the importance of sleep, developed together with the Portuguese Sleep Association. 


\section{SLEEP WELL, SLEEP TIGHT}

Now that you know how, when and why our bodies need to sleep, habits and practices that help to sleep better or that, on the contrary, disturb a good sleep night, existent sleep disorders and what to do in those contexts, there are no excuses to not have a good night of sleep! Do not let a bad sleep night be your kryptonite, superhero!

\section{REFERENCES}

1. Gaspar, L. S., Álvaro, A. R., Carmo-Silva, S., Ferreira Mendes, A., Relógio, A., and Cavadas, C. 2019. The importance of determining circadian parameters in pharmacological studies. Br. J. Pharmacol. 176:2827-47. doi: 10.1111/bph. 14712

2. Hirshkowitz, M., Whiton, K., Albert, S. M., Alessi, C., Bruni, O., DonCarlos, L., et al. 2015. National Sleep Foundation's sleep time duration recommendations: methodology and results summary. Sleep Health 1:40-3. doi: 10.1016/j.sleh.2014.12.010

3. Ramalho-Santos, J., Álvaro, A. R., and Amaral, S. V. 2018. Voyages Without Insomnia. Center for Neuroscience and Cell Biology. Available online at: http://www.cnbc.pt/docs/andrecaetano_layout_BD_SONO_2018__en.pdf

4. National Sleep Foundation. 2020. Sleep Hygiene. Retrieved from: https://www.sleepfoundation.org/articles/sleep-hygiene

5. American Academy of Sleep Medicine. 2014. International Classification of Sleep Disorders. 3rd Edn. Darien, IL: American Academy of Sleep Medicine.

SUBMITTED: 03 March 2020; ACCEPTED: 03 November 2020;

PUBLISHED ONLINE: 01 December 2020.

EDITED BY: Laura Ferraro, University of Palermo, Italy

CITATION: Gaspar LS, Santos B, Barros-Viegas AT, Cardoso J, Varela Amaral S, Carvalhas-Almeida C, Santos-Carvalho A, Cavadas C and Álvaro AR (2020) The Superpowers of Our Sleep. Front. Young Minds 8:540052. doi: 10.3389/frym.2020. 540052

CONFLICT OF INTEREST: The authors declare that the research was conducted in the absence of any commercial or financial relationships that could be construed as a potential conflict of interest.

COPYRIGHT (c) 2020 Gaspar, Santos, Barros-Viegas, Cardoso, Varela Amaral, Carvalhas-Almeida, Santos-Carvalho, Cavadas and Álvaro. This is an open-access article distributed under the terms of the Creative Commons Attribution License (CC BY). The use, distribution or reproduction in other forums is permitted, provided the original author(s) and the copyright owner(s) are credited and that the original publication in this journal is cited, in accordance with accepted academic practice. No use, distribution or reproduction is permitted which does not comply with these terms. 

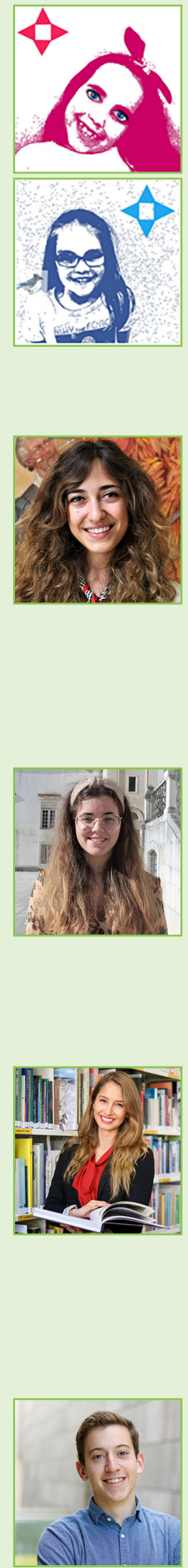

\section{YOUNG REVIEWERS}

\section{ALBA, AGE: 8}

My name is Alba. I am 8 years old and I am from Córdoba, Spain. My hobbies are dancing, singing, cooking, and playing with my brother. When I am older, I want to be either a teacher or a singer, a dancer, or an actress.

\section{MARTINA, AGE: 8}

My name is Martina. I am 8 years old and I am from Spain. My hobbies are drawing, listening to pop music, and skating. When I am older, I want to be a teacher or a famous painter.

\section{AUTHORS}

\section{LAETITIA S. GASPAR}

Laetitia Gaspar received a Bachelor's degree in Genetics and Biotechnology from the University of Trás-os-Montes e Alto Douro (2014) and a Master's in Cellular and Molecular Biology from the University of Coimbra (2016), Portugal. Laetitia has since been working in the sleep field, on Obstructive Sleep Apnea (OSA), one of the most common but highly undiagnosed sleep disorders. For her Ph.D., Laetitia is exploring OSA's impact on cells, while searching for new strategies to improve OSA diagnosis. She has also been actively involved in several initiatives to improve awareness of the importance of sleep.

\section{BÁRBARA SANTOS}

At the University of Coimbra, Bárbara Santos performed her Master's thesis in the Center for Neuroscience and Cell Biology (CNC) in the group of Neuroendocrinology and Aging. Her thesis was focused on sleep and aging, two fields that fascinate her. She is currently working as a researcher at CNC, in the project "NoOSAnoAGEING-Obstructive Sleep Apnea early diagnosis as a new strategy to delay aging." This project focuses on the study of sleep, mainly in obstructive sleep apnea.

\section{ANA TERESA BARROS-VIEGAS}

Ana Teresa Barros-Viegas is a Ph.D. researcher in Health Sciences. Ana got her Ph.D. at the University of Coimbra and University of Liverpool, where she developed a gene therapy strategy for the treatment of Alzheimer's disease. Ana has a strong interest on communicating science not only to peers but also to society, which led her to work in science communication since 2017. Now, Ana is working as a researcher and science communicator focusing on sleep disorders. She is working on creating new, effective strategies to communicate the importance of sleep to our health and quality of life.

\section{JOÃO CARDOSO}

João is a Ph.D. student in Science Communication, currently working at the Science Communication Office of the Center for Neuroscience and Cell Biology (CNC), being in charge of the external communication of the institution. He has been involved in several public engagement and outreach initiatives, and has a strong 

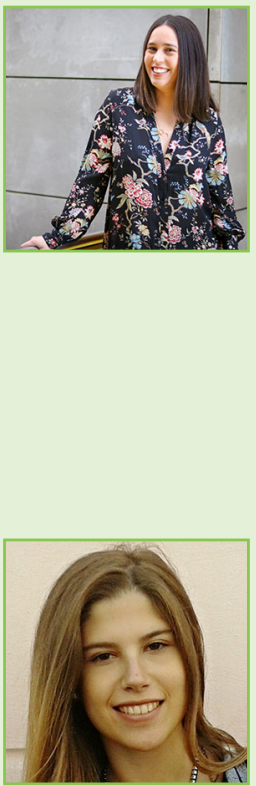

interest in developing innovative strategies to communicate health sciences and raise awareness to diseases. In his Ph.D. project, he is exploring the historical and cultural connection between Portugal and Japan to develop multimedia materials to promote health literacy in both countries.

\section{SARA VARELA AMARAL}

Sara is a Science Communication Office Coordinator with a Master's in Biochemistry and a Ph.D. in Science Communication. She has been involved in several projects that aim to establish innovative strategies to promote communication between scientists and the public, and to foster scientific education in biomedical field. These projects involve interactions with schools, public engagement initiatives, art and science projects, fundraising projects, and impact evaluation studies. At CNC, she has the responsibility of national and international public engagement projects to increase scientific literacy, which could contribute to the construction of a truly scientific culture and citizenship.

\section{CATARINA CARVALHAS-ALMEIDA}

Catarina Almeida has a Master's in Cellular and Molecular Biology from the University of Coimbra. She has worked on several neuroscience related projects at the Champalimaud Foundation Center for the Unknown and Institute of Molecular Medicine, both based in Lisbon, Portugal. Now she is devoted to studying sleep disorders, and in particular, the search for biomarkers to help diagnose sleep apnea obstructive syndrome, at the Center for Neurosciences and Cell Biology of Coimbra, Portugal. She is also committed to communicating science to society and helping to raise awareness of the importance of sleep.

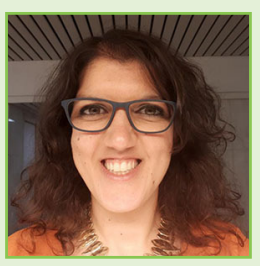

\section{ANA SANTOS-CARVALHO}

Ana Santos-Carvalho is a Ph.D. researcher and science communicator in Health Sciences. Ana studied the protective role of a brain signal in the retina (the back of our eye that senses light and sends information about it to the brain). After her Ph.D., she developed an interface between schools and research centers in Portugal's Institute for Education and Citizenship. Later, she began working with a research team studying sleep disorders. Currently, Ana is coordinating science communication at Institute for Interdisciplinary Research at the University of Coimbra.

\section{CLÁUDIA CAVADAS}

Cláudia has a Ph.D. in Pharmacology and is the Group Leader of the Neuroendocrinology and Aging Group at CNC. She is vice-rector for Research in University of Coimbra and Director of the Institute for Interdisciplinary Research. Cláudia has more than 60 publications and is the principal investigator of several funded projects. She is the former vice-director of the Faculty of Pharmacy at the University of Coimbra. She has scientific experience in the fields of hypothalamus, autophagy, and aging. In the NoOSAnoAGEING project, Cláudia has been establishing the contact between CNC and the CHUC Sleep Unit and is the scientific advisor of the team.

\section{ANA RITA ÁLVARO}

Ana Rita has a Ph.D. in Cellular and Molecular Biology and is a researcher at CNC. She works on projects dealing with obstructive apnea syndrome sleep (OSAS) and other diseases associated with aging. She is the Principal Investigator of the funded project "NoOSAnoAGEING-Obstructive Sleep Apnea early diagnosis 
as a new strategy to delay aging." Ana Rita has a lot of experience in science communication through interaction with the media (radio, TV, and press), organization of World Sleep Day, and participation in Brain Awareness Week and European Researchers' Night. *ritaa80@cnc.cj.uc.pt 